\title{
Asociacionismo vecinal en Jujuy en el tránsito hacia al primer gobierno peronista. Prácticas, continuidades y tensiones
}

\section{Neighborhood associationism in the transit to the Peronista government in Jujuy. Practices, continuities and conflicts}

\author{
Marcelo Jerez \\ Consejo Nacional de Investigaciones Científicas y Técnicas \\ Unidad de Investigación en Historia Regional \\ Investigaciones Socio-históricas Regionales \\ Universidad Nacional de Jujuy \\ (Argentina) \\ mjucasal@gmail.com
}

Este artículo se inserta dentro del conjunto de estudios que analizan el asociacionismo en el tránsito hacia los años del primer peronismo en la Argentina. Tiene como objetivo examinar el asociacionismo vecinal en una de las ciudades más alejadas del centro político porteño: San Salvador de Jujuy. En esta tarea se presta atención a las prácticas asociativas barriales, su labor fomentista y principalmente política; sus instituciones y dirigentes más destacados. Para ello, centramos el análisis en uno de los barrios más antiguos conformado en sus adyacencias y de gran actividad asociativa a principios del siglo pasado: Gorriti.

La idea básica que planteamos aquí es que la actividad asociativa vecinal en San Salvador de Jujuy continuó con intensidad a lo largo de la experiencia peronista. Las tramas en que la misma operó habrían sido herederas de la labor política tanquista desarrollada en años anteriores, siendo configuradas de modo muy particular durante aquel gobierno popular. Esta actividad asimismo no estuvo exenta de tensiones, lo que dejaría ver cómo las entidades asociativas procuraron reservar para sí una cierta cuota de autonomía y de poder decisional.

Palabras Clave: Asociacionismo vecinal - Peronismo - Jujuy 


\begin{abstract}
This article is inserted into a set of studies that analyze the associationism in the years before the emergence of the Peronism in Argentina. It aims to examine the neighborhood associations in San Salvador de Jujuy. Special attention is given to the neighborhood associative practices, its policy and fostering activities; its institutions and prominent leaders. The aim is to deepen the analysis on Gorriti, one of the oldest neighborhoods in San Salvador de Jujuy.

Our hypothesis is that the neighborhood association activities in San Salvador de Jujuy continued with intensity in the first peronist government. It is related to political practices previously developed by the "Tanquismo" in neighborhoods, and configured in a particular way during this popular government. This activity had conflicts, what that showed how the associative institutions tried to preserve their autonomy and decisions in this period.
\end{abstract}

Key Words: Neighborhood associationism - Peronismo - Jujuy

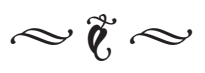

\section{Introducción}

A partir de un crítico estudio de Omar Acha, ${ }^{1}$ los supuestos de Gutiérrez y Romero -en una obra ya clásica- respecto al declive del añejo activismo de las asociaciones barriales durante los años peronistas, fueron revisados. ${ }^{2}$ Así en un posterior trabajo, Romero y De Privitellio matizaban ese argumento sosteniendo la existencia, durante ese gobierno y más allá de la estructura de las unidades básicas, de un amplio y heterogéneo movimiento asociativo

1. ACHA, Omar, "Sociedad civil y sociedad política durante el primer peronismo", en Desarrollo Económico, Buenos Aires, 2004, V. XLIV, № 174, pp. 199-230.

2. GUTIÉRREZ, Leandro y ROMERO, Luis Alberto, Sectores populares, cultura y política. Buenos Aires en la entreguerra, Siglo XXI, Buenos Aires, 1995.

158 de índole variada (bibliotecas, ateneos, sociedades de fomento, entre otras). ${ }^{3}$

Pero esta actividad asociativa sin duda operó en tramas peculiares y complejas en un territorio tan extenso como la Argentina. En este sentido, Acha afirma que dicho asociacionismo continuó vivo aunque extendido desigualmente a todo el país en

3. De este modo, los autores explicaban: "la práctica asociativa pudo desarrollarse en contextos diferentes y potenciar en cada uno de ellos alguno de sus elementos constitutivos. Dicho de otro modo, más que "anidar" en ellas a la democracia, estas asociaciones reflejan en cada coyuntura características del sistema político que tienen causas, razones y explicaciones que las trascienden.” DE PRIVITELLIO, Luciano y ROMERO, Luis Alberto, "Organizaciones de la sociedad civil, tradiciones cívicas y cultura política: el caso de Buenos Aires, 1912-1976”, en Revista de Historia, Mar del Plata, 2005, No 1, p. 33. 
la década peronista. ${ }^{4}$ Estudios recientes, han dado cuenta de este fenómeno, identificando no sólo las especificidades en ciertos distritos provinciales sino también resaltando las continuidades existentes entre la etapa peronista y el lapso previo. ${ }^{5}$ De allí entonces la importancia de profundizar el análisis desde una perspectiva local que permita dar cuenta de las permanencias y particularidades emergentes, sobre todo, en espacios alejados de la región del Litoral, como el Noroeste. ${ }^{6}$

\section{ACHA, Omar, “Sociedad civil...”, Op. Cit.}

5. Las conclusiones de este trabajo así pretenden ser articulables con los resultados de aquellas investigaciones que han analizado esta temática en otros distritos del país, como Mendoza, Córdoba, Bahía Blanca y ciertos pueblos del interior de Buenos Aires. GARZÓN ROGÉ, "Entre la voluntad y el desencanto. Legitimidades tensionadas del vínculo entre las asociaciones obreras y el Estado en Mendoza (1939-1941)", en ACHA, Omar y QUIROGA, Nicolás (coordinadores) Asociaciones y politica en la Argentina del siglo veinte. Entre prácticas y expectativas, Prometeo, Buenos Aires, 2015; MARCILESE, José, "Alianzas, conflictos y facciones del partido peronista en Bahía Blanca, 19481952", en Revista Escuela de Historia, Salta, 2012, V.X, pp. 1-25; BASCONZUELO, Celia, "Organizaciones de la sociedad civil y peronismo local. ¿Cooptación o autonomía? El caso de las asociaciones vecinales de Río Cuarto en tiempos del primer peronismo", en Anuario de la Escuela de Historia Virtual, Córdoba, 2014, Año 5, No 6, pp. 109-129; SALOMÓN, Alejandra, "Instantáneas de participación ciudadana en la esfera local durante el primer peronismo", ponencia presentada en Pre Alas Patagonia VI Foro Sur-Sur, Universidad Nacional de la Patagonia Austral, E1 Calafate, 2014.

6. Los estudios dedicados al asociacionismo en la Argentina tienen una larga historia y no consideramos oportuno enumerarlos aquí. Sin embargo resulta interesante destacar uno de los recientes trabajos que procuraron apreciar el fenómeno en el interior del país, más allá de la tradicional mirada centrada en el conjunto nacional o en las grandes ciudades del Litoral, como fue el caso de la obra de ACHA, Omar y QUIROGA, Nicolás (coordinadores) Asociaciones y politica en la Argentina..., Op. Cit. Por su parte, y en relación a las investigaciones que se aproximan a la temática y al
Con este propósito, en el presente trabajo histórico desplazamos nuestra lente de observación hacia la provincia de Jujuy, donde examinamos la actividad asociativa vecinal en su principal ciudad y capital administrativa: San Salvador de Jujuy. En esta urbe, indagamos sobre las prácticas asociativas barriales, su labor fomentista y principalmente política, sus instituciones y dirigentes más destacados. Para ello, centramos el análisis en uno de los barrios más antiguos conformado en sus adyacencias y de gran actividad asociativa a principios del siglo pasado: Gorriti.

El triunfo de Perón en los comicios de febrero de 1946 coincidió en Jujuy con la victoria electoral del radicalismo yrigoyenista liderado por Miguel Tanco, que apoyaba a aquel coronel en la provincia y que desde años atrás contaba con una significativa impronta en los barrios suburbanos. Por ello, el marco temporal de esta investigación no solo aborda la etapa correspondiente al primer gobierno peronista sino además se vincula con el período precedente procurando develar no solo los conflictos y las rupturas sino también las líneas de continuidades en el desarrollo de las prácticas asociativas barriales.

La idea básica que planteamos aquí es que la labor asociativa vecinal en San Salvador de Jujuy continuó con intensidad durante la experiencia peronista. Las tramas en que la misma operó habrían sido herederas de un trabajo político desarrollado en años anteriores

espacio analizado podemos citar los de JEREZ, Marcelo, "Peronismo y sociabilidad en el Noroeste argentino. La sociabilidad en un barrio obrero de Jujuy (1946-1955)", en Ibídem; "Prácticas asociativas en el Noroeste. Las asociaciones vecinales en Jujuy frente al problema de la vivienda, actividades culturales y fomentismo (19201946)", en Travesía. Revista de Historia Económica y Social, Tucumán, 2010, No 10/11, pp. 225-246. 
por el tanquismo, siendo configuradas de modo muy particular por la influencia de aquel gobierno popular. Esta actividad asimismo no estuvo exenta de tensiones, lo que dejaría ver como las entidades asociativas, procuraron reservar para sí una cierta cuota de autonomía $\mathrm{y}$ de poder decisional.

De este modo, surgen ciertos interrogantes: ¿Cómo se desarrolló el asociacionismo en los barrios suburbanos de San Salvador de Jujuy en la etapa anterior al surgimiento del peronismo? ¿Cómo se expresó su tarea fomentista? ¿La actividad política fue habitual por entonces? ¿Qué implicancias tuvo el comienzo de la administración peronista en la labor de las asociaciones barriales? ¿Cómo influyó este gobierno en las viejas y nuevas entidades asociativas creadas? ¿Quiénes fueron los actores más destacados en aquellos organismos? ¿Qué conflictos emergieron en el interior de esta intensa actividad asociativa?

Con el objeto de responder estas preguntas, a continuación exploramos las prácticas asociativas vecinales en San Salvador de Jujuy en el tránsito hacia el primer gobierno peronista. En esta tarea resaltamos sus principales rasgos, sin descuidar las particularidades y puntos de encuentro con las experiencias acaecidas en otros puntos del país. Temática relevante, en un momento crucial para un activismo civil vigoroso, pero cuyo abordaje en el espacio que nos ocupa no ha merecido esfuerzos de aliento hasta el momento. Las páginas siguientes procuran constituirse en una modesta contribución en ese sentido.

\section{San Salvador de Jujuy y su expansión urbana}

Hacia mediados del siglo XX, la provincia de Jujuy exhibía una importante evolución demográfica, producto del crecimiento natural de su población así como de las migraciones provenientes de otros distritos de la región y de países limítrofes. ${ }^{7}$ Actividades como el azúcar, la minería, el comercio y demás tareas terciarias, contribuyeron a que ciertas localidades se constituyeran en relevantes polos de atracción laboral. Pero en oposición a lo que ocurría en el país en su conjunto, la mayoría de los habitantes jujeños residía en la zona rural, rasgo que compartía con la región del Noroeste. No obstante, dentro de este marco, la provincia mostraba un significativo ritmo de desarrollo urbano. ${ }^{8}$

En el interior del distrito, uno de los departamentos con mayor aumento demográfico fue Capital, el cual triplicó su población de poco más de 14 mil a casi 42 mil habitantes en el período 1914-1947. Por su parte, al centrarnos en las ciudades, constatamos la notoria expansión que evidenció San Salvador de Jujuy. En la etapa transcurrida entre aquellos dos años, su número de habitantes se multiplicó más de cuatro veces (de 7.622 a 31.091). Esta urbe, emplazada entre los ríos Grande y Xibi Xibi -o Chico-,

\section{Ibídem.}

8. En efecto, entre 1914 y 1960, Jujuy junto a Tucumán y Salta, son las que evidencian un elevado ritmo de crecimiento urbano, a diferencia de otras provincias con niveles más bajos como Catamarca, La Rioja o Santiago del Estero. BOLSI, Alfredo (director) Problemas poblacionales del Noroeste Argentino (Contribuciones para su inventario), Instituto de Estudios Geográficos, Tucumán, 1997. 
fue la más poblada hacia 1947, reuniendo al $74 \%$ de los habitantes de su departamento y a más del $50 \%$ de la población urbana de la provincia de Jujuy. ${ }^{9}$

Este fenómeno trajo consigo importantes transformaciones en la ciudad de San Salvador de Jujuy. Su incremento poblacional fue acompañado de una ampliación de la actividad productiva y comercial que se tradujo en el surgimiento de distintos negocios urbanos -talleres, cafés, hoteles, casas de comercio y grandes almacenes-. Ello implicó la aparición de nuevos y diferentes actores sociales, mientras en el área circundante -predominantemente rural-, las actividades económicas aún giraban en torno a la labor agropecuaria.

A diferencia de las grandes ciudades del Litoral, en San Salvador de Jujuy la industria generaba poco empleo, al menos hasta la instalación en 1943 de Altos Hornos Zapla, en las afueras de la ciudad. Indudablemente en su carácter de capital administrativa de la provincia, cobraban cada vez más relevancia las actividades terciarias, ligadas especialmente al empleo público y al comercio. ${ }^{10}$ Fue claro que la urbe capitalina ofrecía ocupaciones alternativas a las vinculadas al azúcar o la minería, sobre todo a quienes provenían del ámbito rural e intentaban probar mejor suerte en sus condiciones de vida.

La llegada del ferrocarril (en 1891), además de impulsar el comercio, permitió el arribo de otros materiales de construcción, modificando

9. JEREZ, Marcelo, "Expansión urbana y el problema de la vivienda en Jujuy en la primera mitad del siglo XX", en TERUEL Ana (directora) Problemas nacionales en escalas locales. Instituciones, actores y prácticas de la modernidad en Jujuy, Prohistoria, Rosario, 2010.

10. Ibídem. así la fisonomía edilicia de la ciudad. Junto a nuevos edificios públicos erigidos (como la casa de gobierno, la estación de trenes o el teatro Mitre), otros cambios continuaron modelando la vida en aquella urbe en las dos primeras décadas del siglo: la dotación de aguas corrientes y cloacas, la provisión de luz eléctrica, así como la planificación del asfaltado que durante los años de 1920 lograba concretarse en las calles céntricas.

El crecimiento poblacional de la ciudad contribuyó de modo relevante a modificar definitivamente aquel viejo casco céntrico. A lo largo de las primeras décadas de la nueva centuria, y en forma progresiva, no quedaron prácticamente espacios libres para construir dentro de la misma urbe. Parte de la población buscó alojamiento en inquilinatos mientras muchos otros comenzaron a desplazarse hacia los suburbios más allá de los ríos circundantes dando inicio a la conformación de los primeros barrios. En estos espacios era común la coexistencia de viviendas medianamente confortables con los llamados "ranchos", casas precarias con características predominantemente rurales. ${ }^{11}$

Los principales vecindarios que comenzaron a poblar la periferia de la urbe capitalina se ubicaban en la margen del río Chico, estos eran Gorriti, Castañeda y Cuyaya. Asimismo, otros asentamientos importantes se hallaban en las riberas del río Grande: Belgrano y San Martín (también llamado Tramontini). Por otro lado, al norte sobre los terrenos altos, se encontraban Ciudad de Nieva y 23 de agosto. Hacia el sur, en una de las áreas más rurales y menos urbanizadas se ubicaban San Pedrito, Las Rosas y Sarmiento.

11. Ibídem. 
Este proceso de conformación de nuevos barrios fue favorecido por varios factores, entre ellos, la construcción de los puentes sobre los ríos Grande y Chico que hicieron posible su comunicación con la zona céntrica. ${ }^{12} \mathrm{De}$ igual modo fue importante la ampliación del recorrido del transporte urbano. Pero sobre todo fue la difusión de venta de lotes privados en cuotas mensuales, y con amplias facilidades de pago, lo que permitió poner los terrenos al alcance de un mayor número de familias. ${ }^{13}$ Sin embargo, cabe señalar que muchas de estas propiedades se hallaban muy próximas a los ríos por lo que eran fácilmente inundables en épocas de lluvia. A ello se sumaba la falta de una correcta provisión de servicios urbanos básicos (tales como agua potable, luz eléctrica o enripiado de calles). Como en otras partes del país, durante las primeras décadas del siglo $\mathrm{XX}$, en procura de paliar estas deficiencias, la gestión de las asociaciones vecinales ante las autoridades estatales, sería fundamental.

\section{Las asociaciones vecinales en los albores de la experiencia peronista}

Al igual que en otros puntos del territorio nacional, el asociacionismo en las principales ciudades de Jujuy se constituyó en una práctica muy intensa a fines del siglo XIX y principios de la centuria siguiente. Dentro de la amplia gama de instituciones surgidas, como la sociedad española e italiana, la sociedad de gimnasia y tiro o el club social, fue también destacada la presencia y el accionar de las sociedades vecinales. En San Salvador de Jujuy,

12. Hacia 1926 ya se hallaban levantados los dos primeros puentes que atravesaban cada uno de los ríos circundantes a la ciudad.

13. La Opinión, San Salvador de Jujuy, 26/08/1938. especialmente, estas organizaciones tuvieron una actividad notable desde el surgimiento de los primeros barrios suburbanos.

En los años de 1930, acompañando la expansión urbana de San Salvador de Jujuy, la labor de estas instituciones cobró mayor notoriedad. Para muchos de los que accedían a un terreno propio en estos barrios, como se ha dicho, no eran pocas las dificultades a enfrentar. En primer lugar no fue sencillo construir. Varias personas -por lo general criollos, inmigrantes o descendientes de los mismoslevantaron sus viviendas de forma precaria o en etapas, ajustándose a la economía familiar. En segundo lugar, esta zona se caracterizaba por la ausencia de servicios; como agua corriente, cloacas o luz eléctrica.

La mayoría de estos barrios contaba con un centro vecinal. No obstante, de acuerdo a las fuentes analizadas, los más activos y cuya tarea adquirió gran resonancia en la prensa local de entonces se hallaban en aquellos vecindarios populosos y ubicados, próximos a la zona céntrica, del otro lado de los ríos Grande y Chico, estos eran: Cuyaya, Gorriti, Castañeda, Belgrano y San Martín. La labor de estos organismos en un área con múltiples necesidades materiales, naturalmente, se orientó sobre todo a gestionar ante las autoridades la ejecución de diversos trabajos públicos.

Pero la interpelación de las asociaciones vecinales al Estado comprendió también solicitudes por otros asuntos, tales como el cambio de nombre a un barrio, políticas sanitarias o la colaboración en un evento benéfico. ${ }^{14}$ Ello sucedió con la acción de los

14. Esta labor fomentista se desarrolló tanto en etapas democráticas como de facto, así sucedió en los años 
vecinos de Gorriti y Cuyaya por una mayor intervención estatal frente a la amenaza del paludismo, ${ }^{15}$ o el pedido de exención de impuestos de una rifa para recaudar fondos destinados a la construcción de una capilla solicitada por la población de la zona sur de la ciudad. ${ }^{16}$ Los periódicos locales se hacían eco de esta tarea de las entidades barriales, así un artículo -por ejemplo- comentaba los logros de

la asociación de fomento de Cuyaya:

La acción de este organismo vecinal se concreta sobre todo a la gestión persistente ante las autoridades para la obtención de las mejoras requeridas... gracias a su actividad se fundó allí una escuela, que funciona con bastante éxito por la concurrencia del elemento en edad escolar. Últimamente la misma Sociedad de Fomento se interesó para que las calles de las villas fueran arregladas mediante trabajos de enripiado, previa nivelación necesaria. ${ }^{17}$

Fue así también común la unión de los habitantes de vecindarios cercanos frente algún problema que concernía a todos. Este fue el caso del pedido de los vecinos de Gorriti, Castañeda y Cuyaya, preocupados por las peligrosas crecidas del río Chico que ya en 1927 habían arrasado un grupo de viviendas de esta zona. En una nota dirigida al gobernador expresaban aquellas inquietudes:

previos al golpe de 1943 y durante ese gobierno militar. Crónica, San Salvador de Jujuy, 07/12/1942; 09/08/1944; 06/10/1945.

15. La Opinión, San Salvador de Jujuy, 26/01/1934.

16. Archivo Histórico de la Municipalidad de Jujuy, Carpetas del Honorable Concejo Deliberante de San Salvador de Jujuy, años 1935-1942.

17. Crónica, San Salvador de Jujuy, 09/08/1935.
Nos dirigimos a V.E. solicitándole se construya una defensa al sud del río Chico... En otros tiempos nuestras poblaciones ya han sido inundadas por fuertes correntadas ocasionando muchas víctimas... Estas poblaciones, como es del conocimiento de V.E. están formadas en su mayoría por obreros industriales, comerciantes y empleados. Tienen escuelas, estafeta de correo, cárcel penitenciaria, puesto de salud, una Iglesia en sus cimientos y edificios de gran importancia... esperamos que se interesará por las necesidades de estas poblaciones, teniendo en cuenta que a costas de grandes sacrificios edificamos nuestras viviendas y que ahora vivimos intranquilos ante el peligro que amenaza nuestras vidas e intereses. ${ }^{18}$

Sin embargo, es posible, que toda esta aventura, no haya sido percibida por muchos vecinos como parte de un proceso exclusivo de "movilidad ascendente". En este sentido, resulta probable que, como sostiene Nieto para el caso de Mar del Plata, fuera vivida también como un "desplazamiento" de los sectores más humildes hacia las zonas semidesiertas de la ciudad. ${ }^{19}$ Así, aquellas familias "desplazadas" hacia los márgenes del ejido urbano sintieron, en distintos modos, dañado su "derecho a la ciudad"20. A comienzos del siglo XX, tal vez, ello se plasmaba en una particular concepción

18. Crónica, San Salvador de Jujuy, 05/09/1935.

19. Nieto, en su análisis de los barrios periféricos surgidos en Mar del Plata, sugiere que la tarea fomentista de los vecinos "no fue vivida como un proceso de movilidad ascendente, sino como un desplazamiento de los "pobretes" por los "más pudientes" hacia zonas "semidesiertas" de la aldea." NIETO, Agustín, "Asociacionismo obrero y popular en la aldea, Mar del Plata (1940-1960)", en ACHA, Omar y QUIROGA, Nicolás (coordinadores) Asociaciones y politica..., Op. Cit., p. 183.

20. Ibídem. 
de lo que estas personas consideraban justo, esto es su derecho a ocupar no sólo los espacios de la ciudad sino también a disfrutar de sus beneficios así como de su equipamiento urbano.

En este sentido, la obtención de óptimas condiciones habitacionales y de vida en los barrios conformó una de las reivindicaciones principales de sus habitantes, no sólo en pos de la ejecución de trabajos de infraestructura urbana (ampliación de luz eléctrica, agua potable, cloacas, enripiado y pavimento, entre otras) sino también de una vivienda digna. En esta tarea, el asociacionismo vecinal cumpliría, indudablemente, un papel fundamental. Precisamente, ese derecho a la ciudad constituiría un componente esencial en el impulso fomentista así como en la temprana labor política de los habitantes de los barrios suburbanos.

En efecto, en los años anteriores a la emergencia del peronismo, las movilizaciones y reuniones políticas en las barriadas fueron muy habituales. Durante las cuatro primeras décadas del siglo pasado la competencia política jujeña se había dirimido, como en el resto del país, principalmente entre radicales y conservadores. El grupo radical, en especial de signo yrigoyenista liderado por Miguel Tanco, fue el que contaba con mayor ascendiente popular y había accedido al gobierno en distintas oportunidades. ${ }^{21}$ De todas formas, a lo largo de este período, fue innegable el poder político que tuvo el partido conservador

21. El período radical en la provincia se desarrolló bajo las administraciones de Carrillo (abril 1918-abril 1921), Córdova (abril 1921-enero 1924), Tanco (septiembre 1929-septiembre 1930) y Bertrés (mayo 1940-enero 1942). así como el uso del fraude al que recurría frecuentemente para mantenerlo.

Miguel Tanco sin duda fue la figura política más convocante por entonces. ${ }^{22}$ Con una vibrante prédica social reivindicaba la lucha de los sectores más sumergidos; según los medios partidarios aquel dirigente encarnaba al "hombre que levantará al obrero y hará feliz la vida del pueblo", el "defensor del proletariado y enemigo de los patrones". ${ }^{23} \mathrm{Su}$ perfil popular opuesto al de los elegantes "caballeros notables", miembros del sector conservador local, contribuyó a ganarse la adhesión de la población humilde de la provincia. En la zona suburbana de San Salvador de Jujuy, su

22. Miguel Anibal Tanco nació en San Salvador de Jujuy el 6 de octubre de 1888, provenía por vía materna de una familia de la elite jujeña, sus padres eran Juan Tanco y Marta Graz Padilla, hija de Macedonio Graz, político y uno de los más ricos propietarios de la provincia. A los 18 años ingresó en la Escuela Naval Militar en Buenos Aires, donde permaneció hasta retirarse del servicio activo en 1923 con el grado de Teniente de Fragata. Al poco tiempo regresa a Jujuy con una misión política encomendada por Hipólito Yrigoyen, del que había sido su edecán: colaborar con el gobernador radical Mateo Córdova. Bajo esta gestión ocuparía diferentes cargos públicos e iniciaría en este distrito una intensa carrera política. Para profundizar el análisis sobre esta figura política véase los trabajos de FLEITAS, María

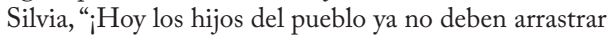
cadenas!”. El radicalismo en Jujuy de los años 20. Miguel A. Tanco, el "hombre que levantará al obrero y hará feliz la vida del pueblo", en Centro de Estudios de Historia Politica, Universidad Nacional de San Martín, 2006. Disponible en: <http://www.unsam.edu.ar/escuelas/ politica/centro_historia_politica/material/fleitas.pdf> [Consulta: 5 febrero 2015]; "Reforma? Revolución? En torno a la lucha política a fines de la década radical en Jujuy", en TATO, María Inés y CASTRO, Martín (compiladores) Del Centenario al peronismo. Dimensiones de la vida politica argentina, Imago Mundi, Buenos Aires, 2010.

23. FLEITAS, María Silvia, “¡Hoy los hijos...”, Op. Cit., pp. 3-7. 
impronta política fue muy notable en los años de 1920 y 1930.

Las necesidades en los barrios, pese a la activa labor fomentista de los vecinos, aún eran importantes. Frente a la insuficiente respuesta de los gobiernos conservadores, Tanco supo interpretar los mayores reclamos de aquella población y convertirse muy pronto en representante de sus intereses. En los actos proselitistas realizados en estos vecindarios, incluía en su plataforma de gobierno la ejecución de una serie de trabajos públicos así como la edificación de un conjunto de viviendas económicas. ${ }^{24}$ De igual modo, en estos eventos, incentivaba a esos sectores sociales a la participación política.

Ciertamente el radicalismo yrigoyenista promovió con éxito en los barrios la movilización de sus habitantes. Los motivos de las convocatorias fueron varios, toda ocasión era propicia para reunir al mayor número de personas posible: la apertura de comités, el apoyo a la sanción o difusión de una ley así como el respaldo a un determinado candidato. El tanquismo recurría constantemente a la impresión de sueltos y volantes, llamando a la participación popular activa, a ganar la calle y los espacios públicos para hacer escuchar sus reclamos. En diversas ocasiones los propios vecinos no solo organizaban los actos sino que participaban además como oradores. ${ }^{25}$

Resulta interesante destacar en este punto como el tanquismo capitalizó con éxito en los barrios esa malla asociacionista ya existente, promoviendo la creación de nuevos organismos eminentemente orientados a la actividad

24. La Vanguardia, San Salvador de Jujuy, 9/05/1930.

25. Ibídem. política. Los centros vecinales, por su parte, no era extraño que aprovecharan tal vínculo para actualizar, reforzar y canalizar sus demandas. De allí, la habitual superposición de funciones, evidentes por ejemplo cuando las reuniones políticas se realizaban en el inmueble donde funcionaba el centro vecinal, convertido al mismo tiempo en comité barrial.

De esta manera, el tanquismo impulsó allí de modo relevante la creación de múltiples instituciones asociativas políticas. En estos espacios, los asistentes fortalecían los lazos de identificación partidaria, sin etiqueta se expresaban en su lenguaje cotidiano sobre diversas cuestiones políticas y sociales. Escuchaban a sus principales dirigentes barriales junto a Tanco que generalmente se hacía presente y preparaban futuras acciones y eventos. ${ }^{26}$

En este contexto, no fueron pocas las personas que, lejos de la indiferencia política que durante años les imputara el conservadurismo, traspasaron la puerta del conventillo o del humilde rancho al otro lado del río para ocupar las calles céntricas en algún acto partidario. Allí, donde cotidianamente concurrían por motivos laborales o comerciales, ahora cobraban visibilidad política. Así, es dable suponer que no solo el tanquismo buscó identificarse con estos sectores sociales, sino también estos mismos individuos anclaron su identidad en un radicalismo yrigoyenista que los incitaba a convertirse en protagonistas políticos.

Los habitantes de las barriadas no constituían un grupo uniforme sino heterogéneo en su composición social, étnica y cultural. Entre

26. Ibídem. 
ellos se contaban trabajadores independientes, empleados de medio o bajo escalafón en la administración pública, comerciantes y peones de las propiedades rurales cercanas. Asimismo, seguramente sus objetivos fueron diversos; romper con aquel modelo de una política para pocos, optimizar sus condiciones de vida a través de un trabajo, de ayuda material para la construcción de una vivienda o mejoras para el barrio en su conjunto. No obstante, su destacada participación política devela ciertos aspectos comunes: el fuerte apoyo al tanquismo así como el cuestionamiento al conservadurismo local.

Los logros políticos de este ascendiente de Tanco se plasmarían en 1946, cuando, apoyando la candidatura de Juan Domingo Perón, participaría en las elecciones de febrero de ese año liderando una fuerza disidente del radicalismo, bajo el nombre de Unión Cívica Radical Yrigoyenista (UCRY). Tanco se presentaría como candidato a senador nacional y designaría a Alberto Iturbe como candidato a gobernador de la provincia. ${ }^{27}$ En estos comicios,

27. A la paradigmática jornada del 17 de octubre en Buenos Aires, le seguiría la formación del Partido Laborista, defensor de los intereses obreros, en el que se apoyaría Juan D. Perón. Mientras tanto en Jujuy, el nombre de Tanco figuraba como uno de los posibles dirigentes del nuevo partido en el ámbito local. La disidencia radical, sin embargo, encabezada por aquel caudillo, tomando el nombre de Unión Cívica Radical Yrigoyenista, decidía brindar su apoyo a Perón y presentarse en los comicios de febrero de 1946 como una fuerza separada del Partido Laborista. Como bien subraya Kindgard, en estos orígenes del peronismo jujeño resaltaba la homogeneidad de la fuerza tanquista y el rechazo de los conservadores a cualquier posibilidad de alianza. Para ampliar sobre esta temática véase: KINDGARD, Adriana, Alianzas y enfrentamientos en los orígenes del peronismo jujeño, Ediunju, San Salvador de Jujuy, 2001; JEREZ, Marcelo, "Entre la juventud y la obra pública. La trayectoria política del primer gobernador peronista en Jujuy: Alberto Iturbe (1940- la mayor cantidad de votos en San Salvador de Jujuy provendrían de los barrios ubicados en su periferia. ${ }^{28}$ Esta victoria electoral no sólo era heredera de una tarea militante previa sino que en los años siguientes se profundizaría, claro está, bajo el particular contexto peronista. Para apreciar con mayor nitidez los rasgos de este fenómeno, centremos nuestra observación en uno de estos vecindarios: Gorriti.

\section{La actividad asociativa en barrio Gorriti bajo el gobierno peronista}

Como se ha dicho, los supuestos planteados por Gutiérrez y Romero acerca de que el activismo de las asociaciones vecinales habría mermado hacia los años peronistas, fueron revisados a partir del análisis realizado por Acha. ${ }^{29}$ La labor participativa de aquellas entidades asociativas, así, lejos de declinar, continuaron con intensidad durante aquel gobierno popular.En este apartado, procuramos no sólo corroborar este argumento en San Salvador de Jujuy sino también dar cuenta de los rasgos que asumió dicha experiencia en un populoso barrio con una importante labor asociativa.

Gorriti fue uno de los primeros vecindarios surgidos a comienzos del siglo pasado en la

1946)", en MACOR, Darío y TCACH, César (editores) La invención del peronismo en el interior del país II, Universidad Nacional del Litoral, Santa Fe, 2013.

28. Un hecho ilustrativo de ello fue lo acontecido en Gorriti donde el tanquismo obtuvo más del $60 \%$ de los votos, mientras la UCR el 11\% y los conservadores el 16\%. Proclama, San Salvador de Jujuy, 02/03/1946.

29. DE PRIVITELLIO, Luciano y ROMERO, Luis Alberto, "Organizaciones de la sociedad...", Op. Cit.; ACHA, Omar, "Sociedad civil...”, Op. Cit. 
periferia de la ciudad capital jujeña y con una distinguida labor asociativa de su población. Tempranamente había conformado un activo centro vecinal cuya tarea se orientó a gestionar diversos trabajos públicos, en especial la construcción de defensas ante los peligros por la crecida del río Chico que se hallaba en las adyacencias. Asimismo, en muy poco tiempo, contó con diversos espacios de sociabilidad vecinal, como una biblioteca, un café y un club deportivo que llevaba el nombre del barrio.

Pero en el lapso previo al surgimiento del peronismo, otras instituciones fueron creadas allí destinadas especialmente a la socialización política. En este sentido, la población de Gorriti evidenció una participación política de la primera hora. Así, en esta zona, funcionaron entidades como el Club de la Juventud Radical o el Centro Obrero Radical, muy nombrados por la prensa opositora en donde no faltaban los calificativos peyorativos para referirse al origen humilde y barrial de sus miembros. ${ }^{30}$

Con el triunfo electoral de la fuerza tanquista en 1946, no pasaría mucho tiempo para que los medios de comunicación presentaran al peronismo como la continuación del yrigoyenismo. ${ }^{31} \mathrm{Al}$ año siguiente, con la creación del Partido Peronista, el secretario de la comisión organizadora del nuevo partido en Jujuy, Carlos Snopek, comunicaba a sus seguidores el abandono de la denominación

30. FLEITAS, María Silvia, "Reforma? Revolución?...", Op. Cit.

31. Como se ha dicho, la victoria electoral de la fuerza política que apoyaba a Perón en Jujuy consagraría a Iturbe como gobernador, función en la que sería acompañado por un equipo integrado por jóvenes $\mathrm{y}$ veteranos dirigentes que habían seguido a Tanco desde los años de 1920. Jujuy, San Salvador de Jujuy, 21/11/1946. tradicional de "radicales". En adelante se adoptaría el nombre derivado del apellido del Líder, por el que "en aquella gloriosa jornada de octubre las multitudes se lanzaron a las calles agitadas: Perón." 32

Los centros de sociabilidad política, así como los de fomento, habían desarrollado bajo la influencia política de Tanco una intensa labor en pos de sus reclamos sociales y políticos. Esta actividad no solo continuó en el tránsito hacia el gobierno peronista, sino que fue reformulada y profundizada. Los vecinos que adherían a aquel viejo caudillo pudieron percibir que el nuevo movimiento político, al igual que por muchos años el yrigoyenismo local, no sólo acompañaba las reivindicaciones populares sino que además proclamaba públicamente constituirse en el garante de su cumplimento. Ello indudablemente influyó de modo notable en el asociacionismo vecinal bajo la órbita peronista.

En este marco en Gorriti, mientras el asociacionismo vecinal continuaba superponiendo sus funciones, entre la labor fomentista y política, la mayoría de los organismos dedicados eminentemente a esta última actividad serían reestructurados pero sin perder su identificación con el grupo tanquista. Así aconteció con el Centro Social y Cultural de la Juventud inaugurado en 1945, el cual en la nueva coyuntura prontamente haría pública su adhesión a Tanco y al peronismo. ${ }^{33}$ De igual modo, nuevas entidades serían creadas en las que podía percibirse, en este momento de transición, la amalgama política aún fresca que daba cuenta de ciertos rasgos particulares de su composición.

32. Jujuy, San Salvador de Jujuy, 18/01/1947.

33. Jujuy, San Salvador de Jujuy, 11/10/1946. 
Al respecto, con motivo de la inauguración de una de aquellas instituciones, un artículo periodístico felicitaba a la "reunión convocada por la mujer radical yrigoyenista a los efectos de dejar constituido el Centro Eva Duarte de Perón." ${ }^{34}$ El gobierno, por su parte, desde un primer momento apoyaría a estas asociaciones afines, de distintos modos, ya sea económicamente o en la gestión de diversas obras o trámites administrativos. ${ }^{35} \mathrm{~A}$ su vez, varios de los compromisos asumidos durante la campaña electoral con Gorriti y otros barrios, serían incluidos en el Plan Cuadrienal de Obras Públicas (1947-1951) diseñado por la gestión peronista provincial. ${ }^{36}$

Múltiples son los ejemplos que dan cuenta de la cercana relación del sector dirigente con las entidades de aquel vecindario. Así, en 1948, el club deportivo del barrio obtenía, de forma expedita, su personería jurídica. Un año antes, el diputado nacional Teodoro Saravia había logrado gestionar la suma de $60 \mathrm{mil}$ pesos $\mathrm{m} / \mathrm{n}$ para la construcción del edificio del Centro Social y Cultural Juana Manuela Gorriti, institución integrada por mujeres donde además de actividades de esparcimiento, aprendían oficios. ${ }^{37}$ A la inauguración de dicho inmueble luego concurrirían el gobernador, ministros, legisladores nacionales y provinciales.

34. Jujuy, San Salvador de Jujuy, 02/02/1947.

35. Jujuy, San Salvador de Jujuy, 21/08/1947.

36. Para profundizar sobre este plan de obras públicas véase JEREZ, Marcelo, "Peronismo, Planificación y Estado en el Noroeste Argentino: Iturbe y el Plan Cuadrienal de Obras Públicas en la provincia de Jujuy (1947-1950)", en Boletin Americanista, Barcelona, 2013, No 67, pp. 163-182.

37. Poco tiempo después a esta asociación se la proveía de un anexo destinado a biblioteca. Jujuy, San Salvador de Jujuy, 12/03/1947.

168
Entre los dirigentes con mayor participación en aquellos centros, se destacaban José Gallardo, Rafael Moreno, Pablo Hoyos, Nolasco Cachagua, Bonifacio Jerez, Augusto Fernández, Arturo Zigarán y los hermanos Luis y Natalio Benítez. Su labor fue relevante en las asociaciones culturales, deportivas y de fomento, donde, sus nombres figuraban entre los principales miembros de las respectivas comisiones directivas. Integraban también las delegaciones que asiduamente entraban en contacto con el sector gobernante, a través de entrevistas personales o de notas enviadas en procura de algún beneficio para el barrio. ${ }^{38}$

Conviene destacar además que muchos de aquellos nombres integraban el equipo directivo de la unidad básica de Gorriti, denominada con el número uno, designación que evidentemente daba cuenta del temprano compromiso político de sus habitantes. Ello también se reflejaba en la relevancia que asumían ciertos encuentros con las autoridades gubernamentales. En esas ocasiones, las reuniones contaban con la presencia del gobernador y otros importantes funcionarios, como ministros de diferentes áreas así como legisladores nacionales y provinciales. ${ }^{39}$

Estos vecinos también procuraron entrar en contacto con las autoridades nacionales. El peronismo sin duda conformó diversos canales de comunicación con sus seguidores con el objeto de consolidar la imagen de un Estado atento a las necesidades populares. Un hecho ilustrativo de ello aconteció, en 1951, cuando

38. Jujuy, San Salvador de Jujuy, 25/09/1947.

39. Así por ejemplo en una de estas reuniones, los vecinos se entrevistaron con el gobernador quien convocó a la misma al ministro de hacienda, a un diputado provincial y al subsecretario de salud pública. Jujuy, San Salvador de Jujuy, 24/10/1953. 
Perón invitó a la población argentina a remitir sugerencias para ponerlas bajo estudio con el propósito de incluirlas en el Segundo Plan Quinquenal. ${ }^{40}$ Desde Gorriti, un reconocido vecino, Arturo Zigarán, enviaba su misiva al presidente con un ambicioso proyecto tendiente a paliar el déficit habitacional. ${ }^{41}$

En Gorriti así también fue relevante la participación de las mujeres y la juventud del barrio. Entre las primeras se destacaban aquellas integrantes del centro femenino, tales como Mercedes López, María Guerrero y Carmen Herrera. Las mismas, además de fomentar labores vinculadas a oficios, como tejido, corte y confección, colaboraban en la organización de diversos eventos con otras asociaciones masculinas y femeninas de la ciudad. En los centros juveniles, por su parte, sobresalieron Benito Canchi, Moisés Barcat, Adolfo Anachuri, Carlos Arce y Gerardo Antequera.

Muchos de estos últimos participaron activamente en el Centro de la Juventud de Gorriti, organizando y formando parte de importantes actos. En uno de ellos, que contó con la presencia de Tanco, dirigentes

40. Para ahondar sobre esta campaña denominada "Perón quiere saber lo que su Pueblo necesita" puede consultarse, entre otros estudios: ELENA, Eduardo, "What the people want: State Planning and Political Participation in Peronista Argentina, 1946-1955", en Journal of Latin American Studies, Cambridge, 2005, V. XXXVII, pp. 81-108.

41. El proyecto de este ciudadano, estipulaba la construcción de una serie de viviendas levantadas en pequeños grupos, desde el barrio Gorriti hasta la Quiaca. "Es de presumir que la creación de estos grupos de casas con sus familias establecidas en ellas, traerían con el tiempo la formación de villas, que luego serán pequeños pueblos y después ciudades." Archivo General de la Nación, Fondo de Secretaría Técnica, caja 62, legajo No 17531/52. y legisladores peronistas, el evento comenzó con las palabras de la representante del centro femenino, Mercedes López, a los que siguieron los de Augusto Fernández y de Benito Canchi. En líneas generales, se resaltó la tarea social, cultural y deportiva realizada desde las distintas asociaciones barriales, subrayando a la vez el valioso aporte brindado por el sector gobernante peronista. ${ }^{42}$

No obstante, la expansión del activismo asociativo constituyó un proceso que contribuyó al surgimiento de ciertas tensiones. Ello aconteció por ejemplo cuando el Centro Social y Cultural de la Juventud, emplazado en la zona céntrica de la ciudad y dirigido por Aníbal Gómez, Salomón Assaf y Rubén Agosti, hizo pública su intención de abrir una filial en Gorriti, el cual estaría integrado en su totalidad por jóvenes "con auténtico sentir peronista." ${ }^{43}$ El repudio por parte de los centros existentes en el vecindario a estas declaraciones se hizo sentir fuertemente por sus principales dirigentes y fue dirimido a la postre a su favor por las autoridades provinciales. ${ }^{44}$

Pero más allá de este tipo de disidencias,

42. Luego tomaron la palabra el diputado Fernando Arnedo, el dirigente Marcos Paz, siendo el acto cerrado por el senador Miguel Tanco. Según las crónicas periodísticas el viejo caudillo se refirió a los beneficios y alcances del Plan Quinquenal para la provincia de Jujuy: "Al terminar su discurso se despidió con sus palabras de siempre, rindiéndole homenaje a Hipólito Yrigoyen y al General Juan Perón.” Jujuy, San Salvador de Jujuy, 19/01/194.

43. Jujuy, San Salvador de Jujuy, 29/06/1947.

44. Asimismo, a mediados de 1947, Marcos Paz promovió la creación del Centro Orientación de la Juventud, el cual muy pronto comenzó a rivalizar con el antiguo Centro Social y Cultural de la Juventud. Jujuy, San Salvador de Jujuy, 18/06/ 1947; 03/07/1947; 05/08/1947. 
la actividad de aquellas entidades de Gorriti continuaría con gran dinamismo durante el gobierno peronista. A la creación de la Central del Partido Peronista, inaugurada por Tanco, le seguiría la de un comedor infantil asiduamente visitado por el gobernador Iturbe. En 1950, con la visita de Eva Perón a la provincia, el club deportivo Gorriti promovería en los diarios locales los festejos en honor a la Primera Dama, invitando "a todos los vecinos de la populosa barriada a concurrir a las 9 horas a la Estación del Ferrocarril General Belgrano, con el fin de tributarle un caluroso recibimiento." ${ }^{45}$

Esta institución también impulsaría diferentes campeonatos deportivos claramente vinculados al régimen gobernante, como la copa Día de la Lealtad o Gobernador Iturbe. ${ }^{46}$ De igual modo, el club aprovecharía la realización de distintos eventos para realizar su tarea militante. Una muestra de ello se dio cuando, luego de la inauguración de una cancha de básquet que contó con la presencia de importantes funcionarios públicos, se procedió a dar a conocer el Segundo Plan Quinquenal, destacando los beneficios que traería su ejecución al pueblo en general y al deporte jujeño en particular. ${ }^{47}$

Con el fin del gobierno peronista, esta añeja tradición asociativa y política de Gorriti no pasaría desapercibida para los sectores golpistas locales. Entre las medidas tomadas por la administración de facto tendientes a borrar todo vestigio que evocara a la "tiranía" depuesta, se hallaría la de disciplinar las actividades de las asociaciones barriales. Todas las instituciones de fomento, deportivas

45. Crónica, Jujuy, San Salvador de 04/06/1950.

46. Jujuy, San Salvador de Jujuy, 16/10/1953.

47. Jujuy, San Salvador de Jujuy, 29/07/1953.

170 $y$ culturales fueron intervenidas por una nueva entidad; la Comisión de Inspección y Asesoramiento de Centros Vecinales. ${ }^{48}$ No obstante, frenar y extirpar aquellas viejas prácticas de participación social y política, fuertemente arraigada en este y otros barrios, ciertamente no sería sencillo de lograr en los años subsiguientes.

\section{Reflexiones finales}

A partir de lo expuesto pudimos dar cuenta de cómo se expresó el asociacionismo barrial en San Salvador de Jujuy durante los años peronistas, fenómeno que, sin embargo, no fue exclusivo de dicho período. En efecto, ya desde principios del siglo pasado, logramos evidenciar en esa ciudad una intensa actividad fomentista, deportiva, cultural y política. Estas prácticas previas, como en otros distritos del país, conformaron formas originales e iniciales de una labor, especialmente en el campo político, que luego con el peronismo se profundizarían..$^{49}$ En este sentido, constatamos altos grados de participación popular a favor del radicalismo yrigoyenista liderado por Miguel Tanco.

Esta figura política, en el ámbito urbano, había logrado una importante presencia territorial en los barrios, promoviendo con éxito el involucramiento político de sus habitantes. Desde antes de la emergencia del peronismo,

48. Libertad, San Salvador de Jujuy, 09/12/1955.

49. Como señala Garzón Rogé en su estudio sobre las prácticas y el acercamiento de las asociaciones obreras con el Estado provincial de Mendoza, entre los años de 1939 y 1941, estas experiencias constituirían el preludio de cambios más profundos que sobrevendrían en dicha relación años después con el surgimiento del peronismo. GARZÓN ROGÉ, “Entre la voluntad...”, Op. Cit. 
la movilización popular fue realmente significativa. Así, el asociacionismo vecinal -y sobre todo durante los años conservadoresconstituyó también aquí, como en el caso marplatense, un "nido de democracia" pero de una forma no liberal, dado que habitualmente se expresó desde los piquetes, las caravanas, en plazas y calles del centro de la ciudad. ${ }^{50}$

Con el inicio del gobierno peronista, la actividad asociativa barrial no declinó sino que continuó con intensidad, si bien en una particular transición de un espacio yrigoyenista hacia uno peronista. Identidades políticas que lejos de diferenciarse comenzaron en Jujuy un peculiar proceso de amalgama. Mientras el nuevo movimiento político se nutrió de dirigentes provenientes del tanquismo, las entidades asociativas, que mantuvieron a gran parte de su equipo directivo, se reconocían, al mismo tiempo, como radicales y peronistas. Ello revelaría ciertas líneas de continuidades en una y otra etapa, más allá de la ruptura que el peronismo, en este y otros ámbitos, luego buscaría afanosamente establecer con el período precedente.

La interacción entre la dirigencia tanquista y los vecinos no sólo se mantuvo sino que se profundizó bajo el mandato peronista. Resulta interesante destacar cómo aquellos últimos, que incluían a mujeres y jóvenes, no fueron meros "peticionantes", sino que además cumplieron, como señalamos, una dinámica labor política. Muchas de estas personas se movilizaban, organizaban reuniones, actos, y tomaban la palabra junto a altos funcionarios estatales.

Esta impronta participativa fue un rasgo

50. NIETO, Agustín, “Asociacionismo obrero...”, Op. Cit. característico de la población de Gorriti, lo que asimismo se plasmó en la puesta en marcha de la primera unidad básica emplazada en la zona suburbana. La misma, fue conducida por dirigentes que habían integrado o formaban parte de centros asociativos ya existentes en el vecindario. Por ello, a diferencia de lo acontecido en otros distritos argentinos, donde existían fuertes rispideces entre las unidades básicas y las sociedades vecinales, aquí dicha relación fue menos áspera. Los mayores conflictos, en cambio, surgirían por otros motivos. ${ }^{51}$

En un marco de expansión de los centros asociativos, las tensiones surgieron ante la iniciativa de instalar en Gorriti nuevas instituciones por parte de un sector de la cúpula tanquista. Es muy posible que esta disposición respondiera a conflictos o internas de tipo organizativo partidario, que también intentaron dirimirse en el plano del asociacionismo. Lo cierto es que los centros barriales mostraron una clara resistencia, después de años de gozar de un buen grado de autonomía, estas tentativas generaron naturalmente ciertas disidencias.

Este tipo de fricciones matizan de algún modo aquella tradicional imagen de un Estado peronista que permanentemente impuso su voluntad de forma rígida a la sociedad. Aquí, evidentemente, fue claro cómo el asociacionismo vecinal en ocasiones se reservó una cuota de poder decisional. Por otro lado,

51. Esta situación fue el caso de lo acontecido en Bahía Blanca o en ciertos pueblos del interior de Córdoba o Buenos Aires donde las vecinales fueron menos permeables a las unidades básicas. MARCILESE, José, “Alianzas, conflictos...”, Op. Cit.; SALOMÓN, Alejandra, "Instantáneas de participación...”, Op.

Cit.; BASCONZUELO, Celia, "Organizaciones de la sociedad...", Op. Cit. 
además, revela como la relación entre las instituciones barriales y el sector gobernante si bien, en líneas generales, fue fluida, no estuvo exenta de tensiones. Al respecto conviene señalar como hacia el final de esta gestión popular, aún con las múltiples políticas implementadas, las necesidades materiales del barrio seguían siendo importantes. ${ }^{52}$

Sin duda quedan varios aspectos por profundizar en investigaciones futuras, tales como aquellos vinculados a las estrategias adoptadas por los dirigentes barriales para continuar su actividad fomentista y política luego de 1955 o al funcionamiento interno de las asociaciones vecinales (cuyas fuentes, como libro de actas, correspondencias, entre otras, aún no disponemos). No obstante, a partir de este trabajo creemos haber avanzado sobre cómo, en un singular distrito del Noroeste argentino, el entramado civil fue permeable al fenómeno peronista, cuyo influjo inundó prontamente y de manera impensada los canales construidos previamente por otro partido político. Ello generó en la sociabilidad local, un complejo proceso de conjunción de identidades políticas y barriales, que no estuvo libre de transformaciones, permanencias $y$ fricciones.

52. En buena medida, ello respondió a la prioridad que, en materia de obra pública, el gobierno otorgó a ciertas áreas (como salud, educación o vivienda) en otras localidades endebles de la provincia (como aquellas ubicadas en Quebrada y Puna). Para profundizar sobre esta temática, véase JEREZ, Marcelo, "Política de vivienda en Jujuy durante el primer peronismo", en BIERNAT, Carolina; RAMACCIOTTI, Karina (editoras) Políticas sociales. Entre demandas y resistencias. Argentina 1930-1970, Biblos, Buenos Aires, 2012. 


\section{Bibliografía}

ACHA, Omar, "Sociedad civil y sociedad política durante el primer peronismo", en Desarrollo Económico, Buenos Aires, 2004, V. XLIV, No 174, pp. 199-230.

ACHA, Omar y QUIROGA, Nicolás (coordinadores) Asociaciones y politica en la Argentina del siglo veinte. Entre prácticas y expectativas, Prometeo, Buenos Aires, 2015.

BASCONZUELO, Celia, "Organizaciones de la sociedad civil y peronismo local. ¿Cooptación o autonomía? El caso de las asociaciones vecinales de Río Cuarto en tiempos del primer peronismo”, en Anuario de la Escuela de Historia Virtual, Córdoba, 2014, Año 5, No 6, pp. 109-129.

BOLSI, Alfredo (director) Problemas poblacionales del Noroeste Argentino (Contribuciones para su inventario), Instituto de Estudios Geográficos, Tucumán, 1997.

DE PRIVITELLIO, Luciano y ROMERO, Luis Alberto, "Organizaciones de la sociedad civil, tradiciones cívicas y cultura política: el caso de Buenos Aires, 1912-1976”, en Revista de Historia, Mar del Plata, 2005, No 1.

ELENA, Eduardo: "What the people want: State Planning and Political Participation in Peronista Argentina, 1946-1955”, en Journal of Latin American Studies, Cambridge, 2005, V. XXXVII, pp. 81-108.

FLEITAS, María Silvia, “¡Hoy los hijos del pueblo ya no deben arrastrar cadenas!”. El radicalismo en Jujuy de los años 20. Miguel A. Tanco, el "hombre que levantará al obrero y hará feliz la vida del pueblo", en Centro de Estudios de Historia Política, Universidad Nacional de San Martín, 2006. Disponible en: <http://www.unsam.edu.ar/escuelas/politica/centro_historia_politica/material/fleitas.pdf> [Consulta: 5 febrero 2015]

FLEITAS, María Silvia, "Reforma? Revolución? En torno a la lucha política a fines de la década radical en Jujuy”, en TATO, María Inés y CASTRO, Martín (compiladores) Del Centenario al peronismo. Dimensiones de la vida politica argentina, Imago Mundi, Buenos Aires, 2010.

GARZÓN ROGÉ, "Entre la voluntad y el desencanto. Legitimidades tensionadas del vínculo entre las asociaciones obreras y el Estado en Mendoza (1939-1941)”, en ACHA, Omar y QUIROGA, Nicolás (coordinadores) Asociaciones y politica en la Argentina del siglo veinte. Entre prácticas y expectativas, Prometeo, Buenos Aires, 2015.

GUTIERREZ, Leandro y ROMERO, Luis Alberto, Sectores populares, cultura y politica. Buenos Aires en la entreguerra, Siglo XXI, Buenos Aires, 1995.

JEREZ, Marcelo, "Prácticas asociativas en el Noroeste. Las asociaciones vecinales en Jujuy frente al problema de la vivienda, actividades culturales y fomentismo (1920-1946)", en Travesía. Revista de Historia Económica y Social, Tucumán, 2010, No 10/11, pp. 225-246.

JEREZ, Marcelo, "Expansión urbana y el problema de la vivienda en Jujuy en la primera mitad del siglo XX”, en TERUEL Ana (directora) Problemas nacionales en escalas locales. Instituciones, actores y prácticas 
de la modernidad en Jujuy, Prohistoria, Rosario, 2010.

JEREZ, Marcelo, "Entre la juventud y la obra pública. La trayectoria política del primer gobernador peronista en Jujuy: Alberto Iturbe (1940-1946)", en MACOR, Darío y TCACH, César (editores) La invención del peronismo en el interior del pais II, Universidad Nacional del Litoral, Santa Fe, 2013.

JEREZ, Marcelo, "Peronismo, Planificación y Estado en el Noroeste Argentino: Iturbe y el Plan Cuadrienal de Obras Públicas en la provincia de Jujuy (1947-1950)", en Boletin Americanista, Barcelona, 2013, № 67, pp. 163-182.

JEREZ, Marcelo, "Peronismo y sociabilidad en el Noroeste argentino. La sociabilidad en un barrio obrero de Jujuy (1946-1955)”, en ACHA, Omar y QUIROGA, Nicolás (coordinadores) Asociaciones y politica en la Argentina del siglo veinte. Entre prácticas y expectativas, Prometeo, Buenos Aires, 2015.

KINDGARD, Adriana, Alianzas y enfrentamientos en los origenes del peronismo jujeño, Ediunju, Jujuy, 2001.

MARCILESE, José, “Alianzas, conflictos y facciones del partido peronista en Bahía Blanca, 1948-1952”, en Revista Escuela de Historia, Salta, 2012, V.X, pp. 1-25.

NIETO, Agustín, "Asociacionismo obrero y popular en la aldea, Mar del Plata (1940-1960)", en ACHA, Omar y QUIROGA, Nicolás (coordinadores) Asociaciones y politica en la Argentina del siglo veinte. Entre prácticas y expectativas, Prometeo, Buenos Aires, 2015.

SALOMÓN, Alejandra, "Instantáneas de participación ciudadana en la esfera local durante el primer peronismo", ponencia presentada en Pre Alas Patagonia VI Foro Sur-Sur, Universidad Nacional de la Patagonia Austral, El Calafate, 2014. 